\title{
A double-blind cross-over trial of trimethoprim and sulphamethoxazole in chronic bronchitis
}

\author{
I A N W. WE B S T E R ${ }^{1}$ \\ University Department of Medicine, Royal Hospital, Sheffield
}

\begin{abstract}
A double-blind cross-over trial comparing trimethoprim-sulphamethoxazole with sulphamethoxazole in patients with chronic bronchitis in their usual state of health showed that the combination was more effective in reducing the volume and purulence of the sputum. Although the patients preferred treatment with the combination, there was no objective improvement in respiratory function. There was a significant incidence of side effects.
\end{abstract}

Trimethoprim (2,4-diamino-5-(3,4,5-trimethoxybenzyl) pyrimidine) has a high affinity for the enzyme dihydrofolate reductase in the bacterial cell (Roth, Falco, Hitchings, and Bushby, 1962), an affinity 10,000-fold greater than for the mammalian enzyme. When trimethoprim is combined with sulphonamide, which acts in the same metabolic pathway by competing with the utilization of para-aminobenzoic acid, the combination is synergistic and bactericidal for a wide range of bacteria. The use of this drug combination has been reported in chest infections by Drew, Hughes, Fowle, and Cassell (1957), Hughes (1968), and Hughes, Drew, Johnson, and Jarvis (1968). Hughes (1969) showed that trimethoprim-sulphamethoxazole was superior to ampicillin in the treatment of acute exacerbations of chronic bronchitis as assessed by changes in the bacterial content, purulence, and volume of the sputum, and the clinical response.

Most chemotherapy trials in chronic bronchitis have studied the changes in the purulence of the sputum and its bacterial content as well as the over-all clinical response (Stuart-Harris, 1968). In some the trials have been on patients in acute exacerbation but in others the patients have been in a chronic phase of illness. Few investigators have performed tests of ventilatory function at the beginning and end of treatment with any degree of regularity. Contrary to expectation, an improvement in lung function does not always accompany a favourable response to antibiotics. Malone, Gould, and Grant (1968) compared ampicillin, tetracycline hydrochoride, and methacycline hydrochloride in acute exacerbations of

'Present address: 37 Cairnes Crescent, East Melvern 3145, Victoria, Australia chronic bronchitis and found that in $50 \%$ of cases ventilatory function did not change; in the remainder, improvement was recorded only slightly more commonly than deterioration, the response being equally variable between the treatment groups. Petersen, Esmann, Honcke, and Munkner (1967), in a controlled study, found that chloramphenicol was of no greater benefit than physiotherapy or potassium iodide in patients with acute exacerbations when the response was assessed in terms of lung function. Howard (1967) and Howard and Astin (1969) have noted that sharp falls in ventilatory function occurring in some patients with chronic bronchitis could not be correlated with chest illnesses for which courses of antibiotics were used.

A number of patients in Sheffield with acute exacerbations of chronic bronchitis were treated with trimethoprim-sulphamethoxazole and, despite a favourable clinical response with clearing of the sputum, the tests of pulmonary function before and after treatment were variable and did not necessarily show improvement. For example, a young man aged 33 years with chronic bronchitis developed an acute respiratory infection due to Staphylococcus pyogenes which responded rapidly to treatment with trimethoprimsulphamethoxazole. The sputum cleared in three days and at the end of the treatment the disordered blood gases returned to more normal values and yet tests of ventilation [forced expiratory volume in $0.75 \mathrm{sec}\left(\mathrm{FEV}_{0.75}\right)$; forced vital capacity (FVC); and peak expiratory flow rate (PEFR)] did not change significantly.

In view of this, it was decided to compare the effect of short courses of trimethoprim-sulphamethoxazole with sulphamethoxazole in patients 
with chronic bronchitis on a double-blind crossover basis. In particular, changes in the sputum volume and purulence, in lung function, and the clinical state were sought.

\section{DESIGN OF THE TRIAL}

Twenty-seven patients were allocated on a random basis to treatment with two tablets twice per day of either trimethoprim, $80 \mathrm{mg}$, plus sulphamethoxazole, $400 \mathrm{mg}$, or sulphamethoxazole, $500 \mathrm{mg}$. Each treatment period was 10 days and after an interval of four to six weeks the patient was treated with the alternative regime. The patients had all been under surveillance before the trial period and were seen between the two treatment periods. The majority have continued under observation. The patients were especially instructed not to use other antibiotics as most of them had reserve supplies at home. During the period of the trial other drug therapy was kept constant; in particular, the dose of prednisolone which one patient was receiving was maintained constant. The smoking habits of the patients did not change during the trial.

THE PATIENTS The patients, whose mean age was 59 (S.D. \pm 9) years, were all outpatients in their usual state of health and most of them had attended the hospital with breathlessnes due to chronic bronchitis for years. All of them fulfilled the criteria for chronic bronchitis (Medical Research Council, 1965) and two patients who had bronchiectasis were excluded from the analysis. Two patients had required hospital treatment for cor pulmonale within the previous nine months but all patients during the period of the trial were stable from the point of view of cardiac function. They all had evidence of airways obstruction. Mean values of function were as follows: $\mathrm{FEV}_{0.75} 0.87$ (S.D. \pm 0.57 ) litres ; FVC 2.10 (S.D. \pm 0.84 ) litres; FEV $_{0.75} /$ FVC $39 \%$ (S.D. \pm 13$)$; total lung volume 6.09 (S.D. \pm 1.09 ) litres; arterial oxygen tension $\left(\mathrm{PaO}_{2}\right) 71.5$ (S.D. \pm 10.7) $\mathrm{mmHg}$ and carbon dioxide tension $\left(\mathrm{PaCO}_{2}\right)$ 41.7 (S.D. \pm 5.6$) \mathrm{mmHg}$. Fifteen patients who had been smoking for a mean period of 46 years were continuing to smoke. Five of these were smoking more than 20 cigarettes per day, and the others were smoking between 5 and 10 cigarettes per day. Ten patients had stopped smoking for an average period of 10 years. These patients had smoked for a mean period of 32 years. Two patients had never smoked.

\section{METHODS}

CLINICAL In the clinical assessment an attempt was made to grade the severity of each symptom or sign at the beginning and end of each period of treatment as follows:

Breathlessness The three grades of breathlessness were:

Grade I shortness of breath when hurrying on level ground or walking up a slight hill

Grade II shortness of breath when walking with others of comparable age on level ground

Grade III forced to rest when walking at own pace on level ground.

Wheeze as a symptom The patient was asked to judge the severity of wheeze based on his own previous experience, and to classify the severity as mild, moderate, or severe. This was scored at each visit.

Cough The severity of cough was graded on its approximate time duration throughout the day:

Grade I morning cough only

Grade II cough throughout the day or night

Grade III cough throughout both day and night.

Audible wheeze According to the area of distribution and the intensity of this sign, audible wheeze was graded as mild, moderate or severe.

Patient preference This was assessed at the end of the trial by asking the patient which course of treatment he preferred from the point of view of respiratory symptoms.

SPUTUM Changes in sputum purulence and volume were noted.

Purulence This was graded macroscopically according to the method proposed by Miller (1963):

M 1 pure mucoid specimen with no suspicion of pus

M 2 predominantly mucoid specimen with a suspicion of pus

P 1 purulent, grade 1, pus amounting to less than one-third of the specimen

P 2 purulent, grade 2, pus amounting to one-third to two-thirds of the specimen

P 3 purulent, grade 3, pus amounting to more than two-thirds of the specimen.

Volume The sputum produced in the first hour each day after rising from bed was collected in transparent plastic containers and the volume was compared with measured volumes in identical containers filled with coloured liquid. In only a few specimens did the volume of froth make the estimation of sputum volume difficult.

In assessing the change in sputum purulence and sputum volume a graph was constructed and the overall change in each 10-day period was assessed by inspection and this was checked by constructing regression lines. 
TESTS OF LUNG FUNCTION These tests were performed at the beginning and end of each treatment period. The FEV $_{0 \cdot 75}$ and the FVC were measured with a Poulton spirometer (McKerrow, McDermott, and Gilson, 1960) and the peak expiratory flow rate with a Wright peak flow meter (Wright and McKerrow, 1959). Samples of arterial blood were taken by direct arterial puncture and the oxygen and carbon dioxide tensions were measured with a Radiometer and Severinghaus electrode.

BACTERIOLOGY The sputum was examined microscopically and cultured at the beginning and end of a treatment period. The culture was taken from the areas which appeared purulent in the specimen.

\section{RESULTS}

A cross-over treatment period was obtained in 19 patients. Three patients did not continue in the trial because of side effects and two patients were withdrawn because they required treatment in hospital for an illness unrelated to chronic bronchitis. The remaining three patients did not attend for a second period of treatment.

Not every patient had all assessments made. In two patients some of the sputum containers were not returned and in three patients there were difficulties in obtaining arterial blood. Each assessment made on the same patient during both treatment regimens is compared in the following statistical analysis.
QUALITATIVE ASSESSMENT The assessments were classified as 'improved' or 'not improved' and the efficacy was assessed by noting where either form of treatment produced an improvement not induced by the alternative regimen (Table $\mathrm{I}$ ).

Most of the patients did not improve with either form of treatment, but in some trimethoprim-sulphamethoxazole was significantly superior at the $5 \%$ level to sulphonamide in reducing sputum volume, sputum purulence, and cough. Significantly more patients preferred treatment with trimethoprim-sulphamethoxazole, presumably because of the reduction in the volume of sputum and the decreased cough.

When the volume of sputum was reduced by treatment this was almost always accompanied by a decrease in sputum purulence. This change usually occurred in patients with initially high sputum volume.

QUANTITATIVE ASSESSMENT It was possible to test whether :

(1) sulphamethoxazole significantly changed the average level of response in a 10-day period;

(2) trimethoprim-sulphamethoxazole significantly changed the average level of response in a 10-day period; and

(3) the changes in the average level of responses differed significantly between two 10-day treatment periods.

The various responses, averaged over patients, are shown in Tables II, III, and IV. None of the

T A B L E I

\begin{tabular}{|c|c|c|c|c|}
\hline & $\begin{array}{l}\text { TM-S-Improved } \\
\text { SMZ-Not Improved } \\
(a)\end{array}$ & $\begin{array}{c}\text { TM-S_Not Improved } \\
\text { SMZ_Improved } \\
\text { (b) }\end{array}$ & No. of Patients & $\begin{array}{c}\mathbf{P} \text { for } \\
\text { Difference between } \\
(a) \text { and }(b)\end{array}$ \\
\hline $\begin{array}{l}\text { Sputum volume } \\
\text { Sputum purulence } \\
\text { Patient preference } \\
\text { Breathlessness } \\
\text { Wheeze (symptom) } \\
\text { Cough } \\
\text { Audible wheezes }\end{array}$ & $\begin{array}{l}5 \\
5 \\
8 \\
3 \\
3 \\
7 \\
3\end{array}$ & $\begin{array}{l}0 \\
0 \\
1 \\
1 \\
3 \\
1 \\
1\end{array}$ & $\begin{array}{l}17 \\
17 \\
18 \\
19 \\
18 \\
19 \\
19\end{array}$ & $\begin{array}{l}0.0312 \text { (sig.) } \\
0.0312 \text { (sig.) } \\
0.0195 \text { (sig.) } \\
0.3125 \text { (n.s.) } \\
0.6562 \text { (n.s.) } \\
0.0352 \text { (sig.) } \\
0.3125 \text { (n.s.) }\end{array}$ \\
\hline
\end{tabular}

TM-S = trimethoprim-sulphamethoxazole. $\quad$ SMZ = sulphamethoxazole.

The patients in whom treatment with trimethoprim-sulphamethoxazole and sulphamethoxazole had an identical effect are not included in the table Sig. = significant. $\quad$ n.s. = not significant.

T A B L E I I

SULPHAMETHOXAZOLE: AVERAGE VALUES

\begin{tabular}{|c|c|c|c|c|c|}
\hline & $\mathrm{FEV}_{0.75}$ (litres) & FVC (litres) & $\operatorname{PEFR}(1 / \mathrm{min})$ & $\mathrm{PaO}_{2}(\mathrm{mmHg})$ & $\mathrm{PaCO}_{2}(\mathrm{mmHg})$ \\
\hline $\begin{array}{l}\text { Initial } \\
\text { Final } \\
\text { Difference } \\
\text { Standard error of difference } \\
t \\
\text { No. of patients } \\
\text { Probability }\end{array}$ & $\begin{array}{c}0.827 \\
0.776 \\
-0.051 \\
0.0354 \\
-1.44 \\
19 \\
0.2<P<0.1\end{array}$ & $\begin{array}{c}1.995 \\
1.911 \\
-0.084 \\
0.0900 \\
-0.93 \\
19 \\
0.4<P<0.3\end{array}$ & $\begin{array}{c}149.4 \\
156.8 \\
7.4 \\
5.890 \\
1.26 \\
19 \\
0.3<P<0.2\end{array}$ & $\begin{array}{l}70 \cdot 5 \\
70 \cdot 1 \\
-0.4 \\
3 \cdot 285 \\
0 \cdot 12 \\
15 \\
P<0.9\end{array}$ & $\begin{array}{c}42.6 \\
43.0 \\
0.4 \\
0.872 \\
0.46 \\
15 \\
0.7<P<0.6\end{array}$ \\
\hline
\end{tabular}


T A B L E I I I

TRIMETHOPRIM AND SULPHAMETHOXAZOLE: AVERAGE VALUES

\begin{tabular}{|c|c|c|c|c|c|}
\hline & $\mathrm{FEV}_{0.75}$ (litres) & FVC (litres) & PEFR $(1 / \mathrm{min})$ & $\mathrm{PaO}_{2}(\mathrm{mmHg})$ & $\mathrm{PaCO}_{2}(\mathrm{mmHg})$ \\
\hline $\begin{array}{l}\text { Initial } \\
\text { Final } \\
\text { Difference } \\
\text { Standard error of difference } \\
t \\
\text { No. of patients } \\
\text { Probability }\end{array}$ & $\begin{array}{c}0.807 \\
0.763 \\
-0.044 \\
0.0349 \\
-1.26 \\
19 \\
0.3<P<0.2\end{array}$ & $\begin{array}{c}2.034 \\
1.805 \\
-0.229 \\
0.0979 \\
-2.34 \\
19 \\
0.05<P<0.02\end{array}$ & $\begin{array}{c}156.5 \\
163.6 \\
7 \cdot 1 \\
6 \cdot 315 \\
1.12 \\
19 \\
0 \cdot 3<P<0.2\end{array}$ & $\begin{array}{c}68.4 \\
67.0 \\
-1.4 \\
3.655 \\
-0.38 \\
15 \\
0.8<P<0.7\end{array}$ & $\begin{array}{c}43 \cdot 0 \\
44 \cdot 8 \\
1 \cdot 8 \\
1 \cdot 175 \\
1.53 \\
15 \\
0 \cdot 2<P<0 \cdot 1\end{array}$ \\
\hline
\end{tabular}

T A B L E I V

COMPARISON BETWEEN TWO REGIMENS IN CHANGES INDUCED OVER 10 DAYS

\begin{tabular}{|c|c|c|c|c|c|}
\hline & \multicolumn{5}{|c|}{ Average Change in 10 Days in: } \\
\hline & $\mathrm{FEV}_{0 \cdot 75}$ (litres) & FVC (litres) & PEFR ( $1 /$ min $)$ & $\mathrm{PaO}_{2}(\mathrm{mmHg})$ & $\mathrm{PaCO}_{2}(\mathrm{mmHg})$ \\
\hline $\begin{array}{l}\text { TM-S } \\
\text { SMZ } \\
\text { Difference } \\
\text { Standard error of difference } \\
t \\
\text { No. of patients }\end{array}$ & $\begin{array}{c}-0.044 \\
-0.051 \\
0.007 \\
0.0549 \\
0 \cdot 13 \\
19\end{array}$ & $\begin{array}{l}-0.229 \\
-0.084 \\
-0 \cdot 145 \\
0 \cdot 1283 \\
-1 \cdot 13 \\
19\end{array}$ & $\begin{array}{l}7 \cdot 1 \\
7.4 \\
-0 \cdot 3 \\
9 \cdot 796 \\
-0.03 \\
19\end{array}$ & $\begin{array}{l}-1 \cdot 4 \\
-0.4 \\
-1 \cdot 0 \\
5 \cdot 144 \\
-0 \cdot 19 \\
15\end{array}$ & $\begin{array}{c}1 \cdot 8 \\
0.4 \\
1.4 \\
1.823 \\
0.77 \\
15\end{array}$ \\
\hline
\end{tabular}

TM-S = trimethoprim and sulphamethoxazole. $\mathbf{S M Z}=$ sulphamethoxazole.

probabilities (two-tailed) reach conventional levels of significance for either agent, or between the two regimens, in these tests of lung function.

BACTERIOLOGY There was a low isolation rate for potential pathogens $(22 \%)$ from the sputum before commencement of therapy, and throughout the trial there was a high incidence of Gram-negative bacteria (approximately 40\%). Trimethoprimsulphmethoxazole eliminated all organisms encountered at the beginning of treatment (Haemophilus influenzae, Streptococcus pneumoniae, Klebsiella pneumoniae, and coliforms) except in one patient. A mixed flora of Gram-negative organisms was found in the latter and Pseudomonas pyocyanea remained after removal of a coliform. One patient grew a coliform after $H$. influenzae had disappeared from the sputum. Sulphamethoxazole failed to eliminate Ps. pyocyanea on two occasions and coliform on one occasion, and Strep. pneumoniae appeared during one period of treatment.

SIDE EFFECTS Five patients experienced side effects with trimethoprim-sulphamethoxazole and none with sulphamethoxazole. Three of the patients who developed side effects had skin eruptions. These were $(a)$ a generalized macular, erythematous rash associated with fever, rigors, arthralgia, pruritus, and mild conjunctivitis; (b) localized patches of erythema with oedema; and (c) a fine, discrete, macular rash. Two patients developed oral symptoms, such as a painful mouth and tongue, and in one, small mucosal ulcers were seen. The patient also developed diarrhoea. One patient had a mild febrile reaction with myalgia. These side effects occurred when the patients were first given trimethoprim-sulphamethoxazole and therefore were unlikely to be due to sensitization to sulphamethoxazole in a previous treatment period. The rashes resembled sulphonamide sensitivity but none developed in patients who received sulphamethoxazole alone. In one patient who had side effects on the combination, a subsequent course of sulphamethoxazole failed to reproduce the symptoms.

\section{DISCUSSION}

This trial suggested that when patients with chronic bronchitis in their usual state of health receive short-term chemotherapy most of them derive no benefit. Yet some patients, particularly those with higher sputum volumes, showed a decrease in the volume and purulence of the sputum when they were treated with the bactericidal combination of trimethoprim-sulphamethoxazole. This effect was statistically superior to treatment with sulphamethoxazole. This suggests that a low-grade bronchial infection was contributing to the excess mucous gland secretion in these patients though this infection was not necessarily revealed by routine bacteriological tests.

The bacteriological results were not helpful in elucidating the therapeutic result further. There 
was a low rate of bacterial isolation which seems to be at variance with most reports of the isolation of pathogens from patients with chronic bronchitis. Angel, Fletcher, Hill and Tinker (1965), however, reported that between illnesses they isolated $H$. influenzae and pneumococci from $21 \%$ of patients with chronic bronchitis. The Sheffield patients had all received previous courses of oral antibiotics such as tetracycline and this may have influenced the frequency of bacterial isolation and the bacterial flora.

As the trial progressed, it was evident that one of the drugs was producing a higher incidence of side effects, effects suggestive of sulphonamide reactions and yet not encountered after sulphamethoxazole alone. This result suggested either that trimethoprim was itself responsible for these effects or that in some way trimethoprim promoted an increased sensitivity to sulphonamide. Such an incidence of side effects as that encountered is at variance with the low incidence reported by others (Drew et al., 1967 ; Hughes, 1968 ; Reeves, Faiers, Pursell, and Brumfitt, 1969 ; Grüneberg and Kolbe, 1969 ; Hughes et al., 1968 ; Hughes, 1969). McCarthy (1969) reported neutropenia in patients with bronchitis treated with the combination. A case of reversible agranulocytosis was reported by Evans and Tell (1969) in a young woman, and this complication was heralded by fever, rigors, and generalized aches and pains which were later followed by an urticarial skin rash-a similar picture to that seen in one of the patients in this series.

Evidence of the role in infection in the deterioration in lung function in patients with chronic bronchitis may be obtained by relating the deterioration in the ventilatory capacity to the incidence of infective exacerbations, and also by studying the effect of chemoprophylaxis on lung function. Howard (1967) found some correlation between the magnitude of the regression coefficient and the number of acute exacerbations requiring antibiotic therapy. Yet in individual patients, acute chest illness had little effect on the overall pattern of the decline in the $\mathrm{FEV}_{0 \cdot 75}$. Burrows and Earle (1969) could not relate information about recurrent respiratory infection obtained by a quarterly questionnaire to the course of the physiological findings or to survival in patients with chronic obstructive lung disease. Indeed, smoking appeared to be more significant in relation to deteriorating ventilatory capacity in these patients (Fletcher, 1968 ; Wilhelmsen, Orha, and Tibblin, 1969). If bacterial infection has a clear role in the reduction of ventilatory function in these patients, then chemoprophylaxis, directed towards reducing the incidence and severity of acute infective exacerbations, should confer this benefit by decreasing the rate of deterioration in lung function. In the Medical Research Council (1966) trial the rate of decline of the $\mathrm{FEV}_{1}$ over a five-year period was unaffected by chemoprophylaxis, and this was confirmed by the findings of Calder, Lutz, and Schonell (1968). Johnston et al. (1969) found that, although the average decline in the $\mathrm{FEV}_{1}$ over a five-year period of winter prophylaxis with tetracycline was less in treated patients, this was not statistically significant. In the present trial, a 10-day course of chemotherapy with trimethoprim-sulphamethoxazole reduced the volume and purulence of the sputum in a significant number of patients with chronic bronchitis. In spite of this, however, the various tests of lung function $\left(\mathrm{FEV}_{0.75}, \mathrm{FVC}\right.$, PEFR, $\mathrm{PaO}_{2}$ and $\mathrm{PaCO}_{2}$ ) did not change significantly. The degree of benefit experienced by the treated patients must therefore remain in doubt.

I thank the patients who cooperated in this trial and Professor Sir Charles Stuart-Harris for his encouragement. I would also like to thank Dr. D. Harris who supervised the bacteriological examination of the sputum and Mr. D. A. Field for the statistical analysis. During the course of the trial the author was in receipt of a grant from the Wellcome Foundation and this is gratefully acknowledged.

\section{REFERENCES}

Angel, J. H., Fletcher, C. M., Hill, I. D., and Tinker, C. M. (1965). Respiratory illness in factory and office workers. Brit. J. Dis. Chest, 59, 66.

Burrows, B., and Earle, R. H. (1969). Course and prognosis of chronic obstructive lung disease. New Engl. J. Med., 280, 397.

Calder, M. A., Lutz, W., and Schonell, M. E. (1968). A five year study of bacteriology and prophylactic chemotherapy in patients with chronic bronchitis. Brit. $J$. Dis. Chest, 62, 93.

Drew, C. D. M., Hughes, D. T. D., Fowle, A. S. E., and Cassell, M. A. (1967). Effective treatment of chronic bronchitis with short-term trimethoprim and sulphamethoxazole. Proc. 5th int. Congr. Chemotherapy, Vienna Al-5a/3:293. Ed. K. H. Spitz and H. Hascheck. Wiener Medizinischen Akademie, Vienna.

Evans, D. I. K., and Tell, R. (1969). Agranulocytosis after trimethoprim and sulphamethoxazole. Brit. med. J., $1,578$.

Fletcher, C. M. (1968). Bronchial infection and reactivity in chronic bronchitis. J. roy. Coll. Phycns (Lond.), 2, 183.

Grüneberg, R. N., and Kolbe, R. (1969). Trimethoprim in the treatment of urinary infections in hospital. Brit. med. J., $1,545$.

Howard, P. (1967). Evolution of the ventilatory capacity in chronic bronchitis. Brit. med. J., 3, 392.

- and Astin, T. W. (1969). Precipitous fall of the forced expiratory volume. Thorax, 24, 492. 
Hughes, D. T. D. (1968). Trimethoprim in the treatment of chronic bronchitis. Tubercle (Lond.), 49, 425.

- (1969). Single-blind comparative trial of trimethoprimsulphamethoxazole and ampicillin in the treatment of exacerbations of chronic bronchitis. Brit. med. J., 4, 470.

— Drew, C. D. M., Johnson, T. B. W., and Jarvis, J. D. (1968). Trimethoprim and sulphamethoxazole in the treatment of chronic chest infections. Chemotherapy (Basel), 14, 151.

Johnston, R. N., McNeill, R. S., Smith, D. H., Dempster, M. B., Nairn, J. R., Purvis, M. S., Watson, J. M., and Ward, F. G. (1969). Five-year winter chemoprophylaxis for chronic bronchitis. Brit. med. J., 4, 265.

McCarthy, O. R. (1969). Neutropenia after trimethoprimsulphamethoxazole for bronchitis. Brit. med. J., 3, 113.

McKerrow, C. B., McDermott, M., and Gilson, J. C. (1960). A spirometer for measuring the forced expiratory volume with a simple calibrating device. Lancet, 1, 149.

Malone, D. N., Gould, J. C., and Grant, I. W. B. (1968). A comparative study of ampicillin, tetracycline hydrochloride and methacycline hydrochloride in acute exacerbations of chronic bronchitis. Lancet, 2, 594.

Medical Research Council Committee on the Aetiology of Chronic Bronchitis (1965). Definition and classification of chronic bronchitis for clinical and epidemiological purposes. Lancet, 1, 775.
Medical Research Council Working Party on Trials of Chemotherapy in Early Chronic Bronchitis (1966). Value of chemoprophylaxis and chemotherapy in early chronic bronchitis. Brit. med. J., 1, 1317.

Miller, D. L. (1963). A study of techniques for the examination of sputum in a field survey of chronic bronchitis. Amer. Rev. resp. Dis., 88, 473.

Petersen, E. S., Esmann, V., Høncke, P., and Munkner, C. (1967). A controlled study of the effect of treatment on chronic bronchitis. Acta med. scand., 182, 293.

Reeves, D. S., Faiers, M. C., Pursell, R. E., and Brumfitt, W. (1969). Trimethoprim-sulphamethoxazole; comparative study in urinary infection in hospital. Brit. med. J., 1, 541 .

Roth, B., Falco, E. A., Hitchings, G. H., and Bushby, S. R. M. (1962). 5-benzyl-2, 4-diaminopyrimidines as antibacterial agents. I. Synthesis and antibacterial activity in vitro. J. mednl. pharm. Chem., 5, 1103.

Stuart-Harris, C. H. (1968). Chronic bronchitis (part 1). Abstr. Wld Med., 42, 649.

Wilhelmsen, L., Orha, I., and Tibblin, G. (1969). Decrease in ventilatory capacity between ages of 50 and 54 in representative sample of Swedish men. Brit. med. J., 3, 553.

Wright, B. M., and McKerrow, C. B. (1959). Maximum forced expiratory flow rate as a measure of ventilatory capacity with a description of a new portable instrument for measuring it. Brit. med. J., 2, 1041. 